Boise State University

ScholarWorks

Computer Science Faculty Publications and

Presentations

$9-2021$

In-Game Social Interactions to Facilitate ESL Students'

Morphological Awareness, Language and Literacy Skills

Yolanda A. Rankin

Florida State University

Sana Tibi

Florida State University

Casey Kennington

Boise State University

Na-Eun Han

Florida State University 


\title{
In-Game Social Interactions to Facilitate ESL Students' Morphological Awareness, Language and Literacy Skills
}

\author{
YOLANDA A. RANKIN, Florida State University, USA \\ SANA TIBI, Florida State University, USA \\ CASEY KENNINGTON, Boise State University, USA \\ NA-EUN HAN, Florida State University, USA
}

Video games that require players to utilize a target or second language to complete tasks have emerged
as alternative pedagogical tools for Second Language Acquisition (SLA). With the exception of vocabulary
acquisition, much of the prior research in game-based SLA fails to gauge students' literacy skills, specifically
their morphological awareness or understanding of the smallest meaningful linguistic units (e.g., prefixes,
suffixes, and roots). Given this shortcoming, we utilize a two-player online game to facilitate social interactions
between Native English Speakers (NES) and English as a Second Language (ESL) students as a mechanism to
generate ESL students' written output in the targeted language and draw attention to their morphological
awareness. Analysis of chat logs demonstrates the game's potential to enhance ESL students' morphological
awareness and other important L2 literacy skills such as word reading accuracy. Both NES and ESL students'
reflections of their gameplay experiences suggest game design modifications that promote ESL students'
willingness to communicate with NES while developing their morphological awareness and practicing their
L2 communication and literacy skills.

CCS Concepts: • Applied computing $\rightarrow$ Interactive learning environments; Computer-assisted instruction; • Human-centered computing;

Additional Key Words and Phrases: English Second Language, game-based learning, dialogue, L2 literacy, morphological awareness, social interactions

\section{ACM Reference Format:}

Yolanda A. Rankin, Sana Tibi, Casey Kennington, and Na-eun Han. 2021. In-Game Social Interactions to Facilitate ESL Students' Morphological Awareness, Language and Literacy Skills. Proc. ACM Hum.-Comput. Interact. 5, CHI PLAY, Article 279 (September 2021), 25 pages. https://doi.org/10.1145/3474706

\section{INTRODUCTION}

One of the challenges of Second Language Acquisition (SLA) is providing ample opportunities for non-native speakers to practice their communication skills in the target or second language (L2) as a means for developing communicative competence - knowing what to say, when to say it and how to say it $[4,5,38]$. Video games that require players to use the L2 to complete game tasks have emerged as alternative pedagogical tools for language learning, creating the genre of game-based SLA [29, 35, 74, 76, 77]. Recreational games such as Massively Multiplayer Online Games (e.g., World of Warcraft), not intentionally designed to promote SLA, feature an immersive

Authors' addresses: Yolanda A. Rankin, Florida State University, 142 Collegiate Loop, Tallahassee, FL, USA, 30294, yrankin@ fsu.edu; Sana Tibi, Florida State University, 201 W. Bloxham Street, Tallahassee, FL, USA, 30294, stibi@fsu.edu; Casey Kennington, Boise State University, City Center Plaza, Boise, Idaho, USA, 83725, caseykennington@boisestate.edu; Na-eun Han, Florida State University, 142 Collegiate Loop, Tallahassee, FL, USA, 30294, nhan@fsu.edu.

This work is licensed under a Creative Commons Attribution International 4.0 License.

(C) 2021 Copyright held by the owner/author(s).

2573-0142/2021/9-ART279. https://doi.org/10.1145/3474706

Proc. ACM Hum.-Comput. Interact., Vol. 5, No. CHI PLAY, Article 279. Publication date: September 2021. 
virtual environment and social interactions between players as they work together to achieve game objectives $[12,23,69,70,72,95,96,98]$. As part of the gameplay experience, players who represent L2 students process information and communicate in the target language in a game world that provides a situated context for language learning where learners can learn about words that concretely refer to physical objects as well as abstract ideas. These in-game social interactions between linguistically distinct players are beneficial for increasing L2 students' proficiency in the target language $[12,68,69,69,70,73,83]$. However, with the exception of vocabulary acquisition $[3,10,26,34,37,48,49,64,71,80,90,92,99]$, much of the prior research in game-based SLA fails to examine other aspects of L2 literacy that are critical for developing L2 students' reading and writing capabilities in the target language $[1,14-16,61]$.

Skilled reading, a critical aspect of L2 literacy, relies on a constellation of linguistic and cognitive factors $[47,63,86]$. One of the established predictors of skilled reading that has received much attention in the past decade is morphological awareness (MA). Carlisle defines MA as the "awareness of morphemic structures of words and the ability to reflect on and manipulate that structure" 6 , p. 194]. A morpheme is the smallest linguistic unit that carries meaning. For example, the word "unbelievable" is composed of three meaningful units, un + believ (e) + able, which are referred to as the "prefix," "base," and "suffix," respectively. MA accounts for unique variance in reading above and beyond phonological awareness and contributes to vocabulary, reading accuracy, and reading speed which are crucial for reading comprehension [7, 8, 20, 21, 42, 44, 46]. Despite being a critical component for the development of L2 literacy, no game studies have explicitly examined how in-game social interactions support L2 students' MA, indicating an underexplored area in game-based SLA research.

In this paper, we conduct an exploratory study to gauge the potential of a two-player online game to promote L2 students' English literacy skills. The L2 game is designed to leverage social interactions between Native English Speakers (NES) and English as Second Language (ESL) students to provide a situated learning experience to enhance L2 students' literacy skills, MA, and willingness to communicate (WTC) with native speakers. Gameplay is centered around the communicative task of one player describing the visual details of an image to a second player while the second player searches for the matching image from a randomly generated list of images. As such, we pose the following research questions:

- Q1: What is the impact, if any, of repeated gameplay on ESL students' L2 language and literacy skills?

- Q2: What is the impact of chat-based social interactions during gameplay on ESL students' morphological awareness?

- Q3: How well does the online game facilitate meaningful social interactions between NES and ESL students?

Leveraging the appeal of games, we conduct a pilot study of four linguistically mixed dyads (i.e., NES matched with ESL student) who participated in four weeks of repeated gameplay and analyze ESL students' chat logs to demonstrate the potential of the two-player online game to enhance L2 students' English literacy skills, their MA and their willingness to communicate (WTC) with NES. Upon completion of the game study, we interview the four NES who talk about their motivations for playing the game and their experiences interacting with their ESL partners. Additionally, the four ESL students engage in a focus group discussion to reflect on their gameplay experiences, offering suggestions for game modifications to better scaffold meaningful social interactions with NES that facilitate L2 literacy skills.

This paper makes two specific contributions. First, we replace the threat of face-to-face interactions with a game-based chat window interface to offer some degree of anonymity to encourage 
ESL students to interact with NES, giving them an opportunity to practice their L2 communication skills. Second, we utilize this two-player game with a visual context to generate and collect ESL students' written output for assessment of L2 literacy, including vocabulary acquisition, spelling, word reading accuracy and morphology. Results suggest that the game has the potential to positively affect ESL students' learning outcomes.

\section{RELATED WORK}

In this section, we provide a brief overview of prior chat-based interactions in games as a mechanism for language learning and the importance of morphological awareness (MA) and willingness to communicate (WTC) in developing L2 students' language and literacy skills.

\subsection{In-Game Social Interactions to Facilitate SLA}

Communicative competence, the learner's ability to determine the appropriate use of language based on circumstances, is crucial to developing conversational skills in the target language $[2,4,5]$. Games promote social interactions between players to support the development of L2 students' conversational skills as well as different aspects of literacy in the targeted language. For example, Zheng et al. [96] conducted a game study of Quest Atlantis, examining its ability to engage elementary children in sensory stimuli (i.e., graphs, sound, storyline) to support English language acquisition. Culbertson et al. [18, 19] and Li \& Yang [53] created 3D games to assist players with learning Japanese vocabulary and conversational phrases as well as Japanese culture via social interactions with Non Player Characters (NPCs). Several studies of massively multiplayer online games $[67,68,70,73]$ demonstrated that social interactions between ESL students and NES during gameplay scaffold and significantly increase ESL students' vocabulary acquisition compared to those ESL students who choose to not interact with other players. Other studies utilized games to teach pragmatics $[33,58]$, including helping Spanish students to recognize when an apology is warranted and how to articulate such an apology given a real-world scenario [84, 85]. Additionally, research shows that the affordances of chat-based game interactions contributed to an increase in L2 students' motivation and written output while reducing communication anxiety [25, 28, 36]. Embodied learning has emerged as a novel way to engage L2 students in leveraging physical motion in a classroom setting to promote collaborative learning activities that increase L2 students' vocabulary acquisition $[40,48,49]$.

In addition to vocabulary acquisition [91, 98], literacy skills such as reading and writing also serve as building blocks for developing communicative competence in the targeted language. L2 learners need to know "the way in which the particular grammatical forms may be used to express these functions appropriately," [5, p. 2]. In the context of gaming, Cornille et al. [16] examined how web mini-games assist L2 students with grammatical construction to reinforce English writing skills. Allen et al. [1] used games to motivate L2 students to practice their writing capabilities (e.g., paraphrasing, planning, cohesion, etc.). In another game study, gameplay enabled English language learners to practice their business writing skills [55]. Some game studies have scrutinized how well games facilitate vocabulary acquisition to support L2 students' reading comprehension skills $[9,78,83]$. However, none of these game studies explicitly examine L2 students' morphological awareness skills. This paper seeks to fill that gap.

\subsection{The Importance of Morphological Awareness in L2 Literacy}

Morphology refers to the aspect of language that deals with "word-formation processes, including inflections, derivations, and compounds" [62, p. 4] and provides cues to the meaningful parts of words which are known as morphemes. These morphemes can be free in the sense that they stand on their own (e.g., base of a word such as "bake") or can be bound when they are part of a word (e.g.,

Proc. ACM Hum.-Comput. Interact., Vol. 5, No. CHI PLAY, Article 279. Publication date: September 2021. 
the suffix -er in the word "baker"). Other examples of bound morphemes include different prefixes and suffixes. The ability, implicit or explicit, to attend to the different morphemes in words is referred to as morphological awareness (MA) [6]. MA has been confirmed to play a significant role in L2 language and literacy across different languages and abilities [6-8]. Hence, MA or attention to words, especially in the context of communication skills, has been shown to be a key component of L2 literacy skills $[45,54,62,86]$.

Reading comprehension, the ultimate goal of reading, is considered a complex skill [32] in which vocabulary and MA play a key role $[66,94]$. Vocabulary knowledge becomes a major obstacle in second language learners (L2) with lower proficiency levels [51] which in turn contributes to reading comprehension difficulties in the target language [88]. One of the promising venues towards improving L2 students' vocabulary knowledge, word recognition, and reading comprehension is morphological intervention [17, 30, 47] because it enhances vocabulary quantity and quality [54] Morphological intervention functions as mechanism for analyzing words into smaller meaningful units and for understanding their syntactic information using context clues in the sentence, their parts of speech (e.g., a noun as opposed to a verb or adjective) and their meaning. Indeed, empirical evidence confirms that MA plays a role in reading comprehension via three different mechanisms: 1.) morphological analysis [52]; 2.) the ability to decode complex words accurately [21,52]; and 3.) reading vocabulary [31, 43]. Zhang \& Koda [93] also show that adult English language learners' MA contributes to their L2 vocabulary via morphological analysis which is defined as "the ability to infer the meanings of unfamiliar morphologically decomposable words while reading" [94, p. 5]

Although research has confirmed the role of morphology in reading across different languages and multilingual learners $[17,86,94]$, there is still a need to investigate the role of morphology in improving different reading outcomes via gameplay. This is particularly important in light of the empirical evidence that reveals that morphological problem solving skills (e.g., morphological analysis and decoding) are instrumental in vocabulary growth in English language learners [94]. Different morphological structures (e.g., plural vs singular, past vs present, and complex words that can be broken down to multiple morphemes belonging to the same morphological family) can all be embedded in games as techniques to enhance morphological skills which in turn will benefit multiple literacy skills (vocabulary, spelling, and reading comprehension). Indeed, theoretical frameworks describe morphology as the linguistic aspect that binds structure with meaning [44] For example, when L2 learners encounter the bound suffix "-er" in words such as "teacher", "dancer", "baker", etc., L2 learners will form connections between the encountered letter patterns (e.g., suffix -er) and their meaning which in turn facilitates recognition of such multimorphemic words and their meaning. Thus, embedding a wide range of morphological structures may facilitate reading complex words, learning more vocabulary, and understanding their meaning which play a key role in adults' reading comprehension [94].

Writing, as opposed to speaking, involves a reflective process in which the L2 student not only generates output, but has the opportunity to identify errors and correct them before sharing the written output with others [41]. Writing in the target language provides insights into a L2 student's individual cognition and their linguistic capabilities such as syntax and morphology, making a chat-based game environment ideal for collecting L2 students' writing samples. However, few game studies have closely scrutinized chat-based interactions to determine their ability to promote other aspects of L2 literacy skills (e.g., MA) that are crucial to reading comprehension $[1,13,16,56]$.

\subsection{Games as a Mechanism to Encourage Willingness to Communicate}

L2 teachers seek alternative means for providing students with ample opportunities inside and outside of the classroom to develop their conversational skills in the targeted language. Applying willingness to communicate (WTC) theory [22, 75], Peng [65] demonstrates that English as Foreign 
Language students are less likely to communicate verbally in English in the classroom setting when they lack confidence in their ability to carry a conversation with native English speakers. Likewise L2 students are resistant to communicate in the L2 when they suffer from language anxiety-fear of saying the wrong thing and being embarrassed due to mistakes or incorrect use of L2 language $[65,75,97]$. Resistance to WTC can, to some degree, be attributed L2 students' apprehension towards communicating face-to-face with NES [22]. Games that facilitate chat-based social interactions offer a degree of anonymity by hiding players' real identity which serves as a buffer for language anxiety that L2 learners may experience when interacting face-to-face with native speakers [57]. Our proposed solution is to create an opportunity for ESL students to interact with Native English Speakers (NES) while playing an online two-player game. The gameplay experience provides a situated, visual context for ESL students to generate written output and practice their English literacy and communication skills in an interactive, fast-paced learning environment. Additionally, chat-based social interactions draw ESL students' attention to NES' written words in an attempt to enhance their MA, a critical literacy skill that is directly tied to L2 vocabulary acquisition and reading comprehension. Thus, the game is designed to promote repeated gameplay and encourage ESL students to communicate willingly with NES, an understudied pedagogical approach in game-based SLA [35].

\section{OVERVIEW OF THE ONLINE TWO-PLAYER GAME}

We gamify an existing chat framework to provide a social context for L2 literacy and motivation for two linguistically different players to interact with one another as the basis for gameplay. The initial design modifications are each described below.

\subsection{System Configuration}

Because the original chat framework supports synchronous online communication, players are required to have reliable Internet access to play the game. The game is hosted on a Heroku server (free) to support multiple dyads playing online at the same time. We created a MySQL database to automatically store each player's chat logs for each gaming session and the amount of time each player spent playing the game. Players can log into the game from their personal computers, desktop stations or laptops. However, the game can only be played when two players are available to play and log into the game within the same 20 -second window.

\subsection{Individual Player Account}

When the player initially logs into the game, the player creates a login ID used to keep track of the player's chat messages and time spent playing the game. The player also identifies if she is a native or non-native English speaker to ensure that the game pairs linguistically distinct players for each gaming session.

\subsection{Game Objective, Instructions \& Rules}

Similar to Verga \& Kotz's game study of using pictures to facilitate vocabulary acquisition [87], this two-player game has a distinctly different game objective. The instructions and rules for playing the game are displayed on the screen after each player has logged into the game. Instructions explain that Player 1 sees only one image at a time displayed on the screen whereas Player 2 searches through a series of images to find the matching image displayed on Player 1's screen. (See Figure 1.) Player 1 is responsible for describing as many details of the image displayed on the screen to Player 2. Player 2 can ask questions, request more information, etc. to help her find the image displayed on Player 1's screen. Players communicate with one another via the chat-box displayed on the right side of the screen. (See Figure 1.) For example, Player 1 sees an image of a kitchen with 

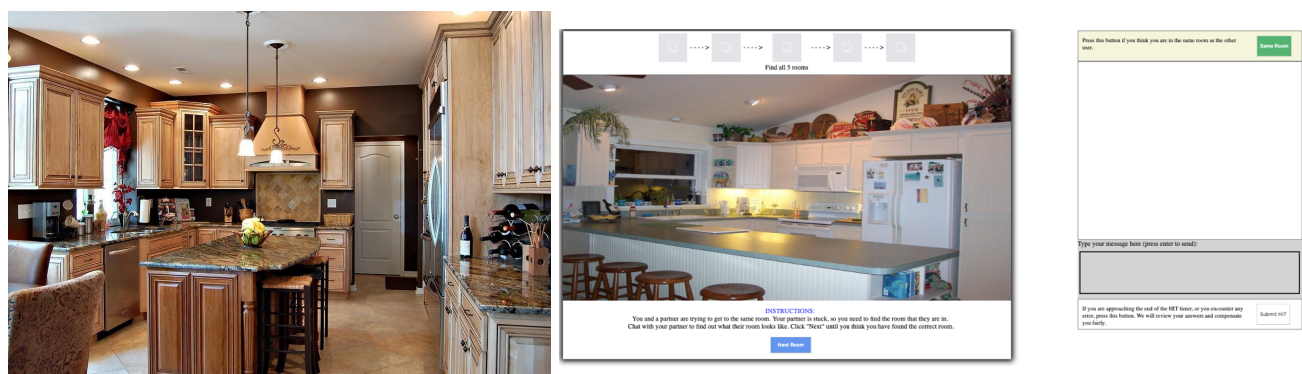

Fig. 1. Player 1 on the left sees this image of a kitchen displayed on her screen while Player 2 searches through a series of images of kitchens to find the matching image. The box on the right is the chat window.

an island, 2 bar stools, granite countertops, oakwood cabinets, and tile floors. Player 1 describes the objects in the room using the chat window to help Player 2 find the same image. Meanwhile, Player 2 searches through a series of images of kitchens, asking questions as needed (e.g., "Is there a wooden table in the kitchen?") to find the same room. (See Figure 1.) Player 1 either confirms or provides additional information about the objects in that particular room (e.g., "No, but there are 2 bar stools with black legs."). If Player 2 thinks she has found the corresponding image, then she presses the SUBMIT button for confirmation. If the images match, then Player 1 sees a new image on her screen and Player 2 repeats the process of finding the same image out of a set of predetermined images.

\subsection{Topical Pictures as the Social Context for MA}

Game content consisted of high resolution pictures (compliments of unsplash.com) which represented more than 10 different topics (e.g., bathrooms, kitchens, musical instruments, classrooms, restaurants, retail stores, board games, food). These topical pictures stimulated conversations between the two linguistically distinct players while providing a social and visual context to support student development of L2 literacy skills. Each game session included five sets of randomly selected pictures around a chosen topic (e.g., a total of 25 random pictures of different bathrooms for one game session). The game randomly selects the topic for each game session. To accomplish the game's objective of finding the matching image, Player 1 should describe the specific details of an image. The selection of pictures was intended to draw students' attention to their morphological awareness. For example, we selected images that contained the singular and plural forms of English vocabulary words (e.g., vase vs. vases or knife vs. knives). See Figure 2. We also chose images of people performing specific activities to promote players using present continuous tense (e.g., using the suffix -ing). See Figure 2 of an image where the person is chopping cilantro.

\subsection{Additional Features}

We created a hidden timer to keep track of how much time each student spent playing the game. This information was stored in the database. Player information such as log ID and time spent playing the game were displayed when the player exited the game. Because we were unsure about how to motivate students to play the game long-term, and likewise we did not want to discourage real-time communication between players for the sake of completing the game objective, we decided not to include a scoring or rewards mechanism in the initial game prototype which is common in socially interactive games (e.g., role-playing games)[27]. 

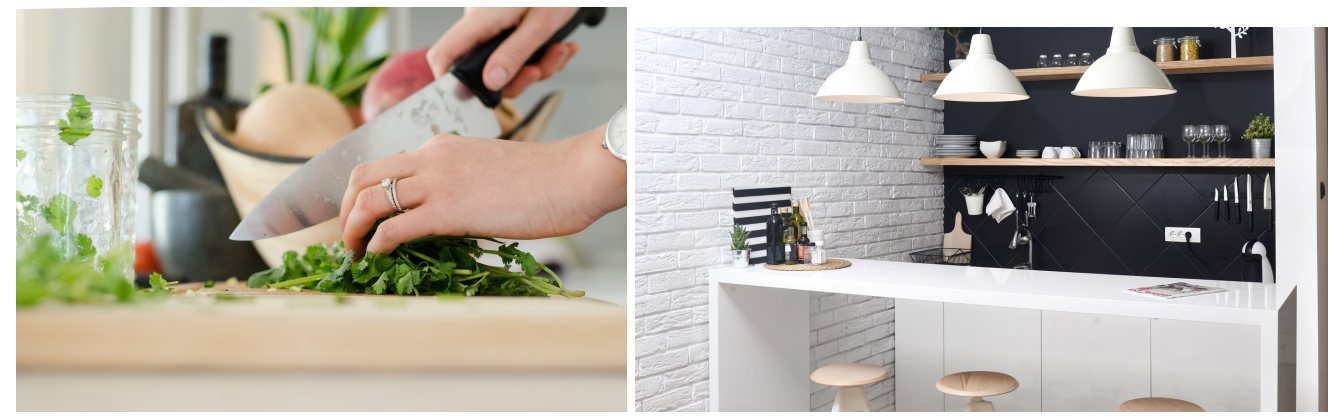

Fig. 2. The first image on the left shows a person using a knife (singular form) to chop cilantro whereas the second image on the right shows different kinds of knives (plural form) hanging on the wall in the kitchen.

\section{METHOD}

Our research goals were to gauge: 1. the impact of repeated gameplay on ESL students' L2 language and literacy skills (RQ1); and 2. the impact of in-game social interactions on ESL students' morphological awareness (RQ2). We conducted a pilot study of the L2 game prototype designed to engage two linguistically distinct players in conversation-based interactions as the basis of gameplay. The pilot study provided a platform to collect ESL students' written L2 output and investigate how well the game promoted or inhibited real-time written conversations between NES and ESL students (RQ3).

\subsection{Setting \& Participants}

Though this particular study features an online L2 game, we began recruitment efforts on a college campus located in the southeastern United States, targeting ESL students enrolled in the college's English Learning Program. After receiving IRB approval, we gave presentations to instructors and ESL students about the game study, asking ESL students to become part of the game design process by playing the game and providing feedback about their experiences. One of the co-authors, a native Arabic speaker, served as an interpreter to ESL students who were also native Arabic speakers (the largest population of ESL students in the college English Learning Program) and answered questions about the game study. We emphasized the time commitment and asked potential participants to be willing to play the game 2-3 times a week for at least four weeks. The criteria for inclusion in the study was informed consent (signed IRB form) and being an English language learner who had spent at least one year learning English as a second language.

We recruited four ESL students, two males and two females ranging in age from 23 to 29 years old to play the online L2 game. Three participants were native Arabic speakers and one participant was a native Vietnamese speaker. Students' test scores on the Test of English as a Foreign Language (TOEFL) ranged from 42 to 72 out of a maximum score of 120 . None of the participants showed any signs of hearing, visual, or language impairment. Though the sample size $(\mathrm{N}=4)$ is too small to derive statistically significant learning outcomes, a small sample size is appropriate for this initial phase of game design where the goal is to develop "a deep understanding of the game's foundation" [27]. We recruited four NES college campus students to partner with the four ESL students during gameplay. Finally, we recruited four more ESL students to represent the control group.

\subsection{Procedure}

After signing the IRB consent form, the control group and the experimental group were administered a battery of tests that represented the pre-assessments for English language and literacy skills. 
Participants in the experimental group provided days and times of availability to play the online game 2-3 times each week for 4 weeks and background information concerning their native language, levels of English proficiency and TOEFL scores. Next, we assigned linguistically mixed dyads based upon matching availability prior to the first game session and created a \#GroupMe chat group to allow participants to communicate with the research team or each other in case there were technical difficulties or unexpected events that required them to reschedule the gaming session with their partner. Each dyad was required to play the game twice a week with the option of playing the game more frequently if their schedule permitted them to do so. All participants received emails an hour before the game session was scheduled to begin. Participants logged into the game using a self-created identity (player ID) at the scheduled time. One game session consisted of five different rounds of 2-3 topics in which each dyad worked together to find the matching images. For example, one round consisted of 25 images of bathrooms, 25 images of bedrooms and another 25 images of kitchens. At the end of the four weeks of gameplay, we collected all of the game chat logs for data analysis. We concluded the game study with a focus group discussion of ESL students and semi-structured interviews with NES. The post-assessments were conducted five weeks after the pre-assessments. Participants were compensated for their time upon completion of the pilot study.

\subsection{Data Collection \& Analysis}

4.3.1 Pre and Post English Language \& Literacy Assessments. All assessments were conducted before gameplay began and after the end of data collection. Assessment instructions were given to the participants individually and orally in English by a previously trained native English speaking research assistant. Assessments were conducted in a quiet, designated classroom. The assessment battery required about an hour to complete for each participant. Each assessment battery included tests in vocabulary, spelling, word reading and morphological awareness (MA).

The Peabody Picture Vocabulary Test (PPVT) [24] is a standardized receptive vocabulary measure. Participants were orally tested on 228 items. The test was discontinued when participants made eight incorrect responses within the same set (which includes 11 items). Each item consisted of a page with four pictures. The participant was given the target word and instructed to point to the picture that they thought best represented the target word. The PPVT was completed individually and orally in English with a practice question given before the graded assessment. The participant's score on the PPVT was the total number of correctly identified items. The PPVT required about 45 minutes for each participant.

A 20-item written spelling test (SPELL) was developed by the authors and given to the participants to measure their ability to spell words in English. The words chosen were relevant to the video game and delivered orally in English. A written response was produced by the participants who were asked to spell the spoken word to the best of their ability. The participant's score on the spelling test was the total number of correct responses. The spelling task required about five minutes for each participant.

The word reading task (WORDREAD) [89] was an oral measure developed by the authors that included 20 words chosen due to their relevance to the video game played by participants. Participants were instructed to read aloud the words at a natural pace. Incorrect pronunciations were noted and the time required by each participant to complete the task was recorded. The participant's score on the word reading assessment was the total number of words correctly pronounced. The word reading task required about five minutes for each participant.

The oral measure of Morphological Awareness (MA) [6] consisted of a 15-item sentence completion task. The instructions and assessment were completed individually and orally in English with a practice question preceding the graded task. Participants were provided with a word and a 
sentence with a blank. Participants were instructed to use the given word to make a new word that worked with the sentence (e.g. "Farm. My uncle is a [blank]." The correct response would be "farmer"). The number of correct responses was the participant's score. The MA task required about five minutes for each participant to complete.

4.3.2 Systematic Analysis of Language Transcripts (SALT). Game chat logs were generated automatically by each participant and transferred to the Systematic Analysis of Language Transcripts (SALT) [60] software. Over the course of the pilot study, the ESL students generated a total of 972 chat messages (utterances). See Table 2. They were then formatted to SALT protocol, coded, and analyzed. Bound morphemes, missing bound morphemes and free morphemes in an obligatory context were identified during the formatting stage. Once formatted and coded, the transcripts were analyzed using the following SALT reports: Omissions and Error Codes (OEC), Word and Morpheme Summary (WMS), and the Standard Measures Report (SMR). Parenthetical remarks were excluded from analysis and all transcripts were organized into Communication Units (C-units). $\mathrm{C}$-units were used to organize the language transcript with one $\mathrm{C}$-unit containing a main clause and its dependent clauses [59].

4.3.3 Focus Group Discussion with ESL Students. Because we thought it was important to elicit feedback about the L2 online game, we attempted to conduct semi-structured interviews, only to discover that the ESL students preferred to participate in a focus group discussion to better accommodate their busy schedules. The focus group discussion took place at a time and location of the ESL students choosing. During the focus group discussion (which was conduected in English), we encouraged the ESL students to reflect on their gameplay experiences by responding to a series of questions (e.g., What did you like about your gameplay experience? What did you think about your partner? What suggestions do you have for improving the game?). The one-hour focus group discussion was recorded and transcribed for content analysis purposes. Adopting a provisional approach to coding [79], two researchers conducted a content analysis of the focus group discussion across the provisional categories of likes, dislikes and suggestions over multiple phases. The coders met at the end of each phase to discuss new emergent themes and resolve any coding conflicts. We identified a total of seven emergent themes to identify ways in which gameplay can better facilitate ESL students' L2 literacy.

4.3.4 Semi-structured Interviews with NES. It was important to collect feedback from both linguistically distinct groups of players. We conducted semi-structured interviews with three of the four NES because one NES was unavailable to meet for an interview due to schedule conflicts. We asked several questions about their gameplay experiences to guide the interview:

(1) What motivated you to participate in this game study?

(2) How would you describe your gameplay experience?

(3) What did you like about your gameplay experience?

(4) What did you not like?

(5) How can we improve the gameplay experience?

Interviews were an average of 30 minutes long. All three interviewers were recorded and transcribed for data analysis purposes. One researcher conducted content analysis of each interview, identifying emergent themes across all three interviews.

\section{FINDINGS}

Using a mixed-methods approach, we organize the findings into three primary categories:

(1) English language \& literacy assessments;

(2) SALT analysis of ESL students' chat logs; 
(3) Quality of social interactions between players.

\subsection{Results from English Literacy Assessments}

For research question 1 (What is the impact of gameplay, if any, on ESL students' L2 literacy skills?), we calculated descriptive statistics for both the experimental $(\mathrm{N}=4)$ and control $(\mathrm{N}=4)$ groups for each assessment. See Table 1.

\begin{tabular}{|l|l|l|l|l|l|}
\hline \multicolumn{6}{|c|}{ Table 1. Pre and post descriptive measures for the experimental group } \\
\hline Assessment & $\mathrm{N}$ & Minimum & Maximum & Mean & $\begin{array}{l}\text { Standard } \\
\text { Deviation }\end{array}$ \\
\hline PPVT & 4 & 75 & 102 & 91.75 & 10.966 \\
POST PPVT & 4 & 78 & 113 & 92.50 & 15.610 \\
VOCAB & 4 & 26 & 34 & 29.25 & 3.594 \\
POSTVOCAB & 4 & 27 & 36 & 32 & 4.243 \\
SPELL & 4 & 3 & 7 & 5 & 1.633 \\
POSTSPELL & 4 & 6 & 9 & 7.5 & 1.291 \\
MA & 4 & 9 & 12 & 10 & 1.414 \\
POSTMA & 4 & 10 & 14 & 11.50 & 1.915 \\
WORDREAD & 4 & 8 & 15 & 12 & 2.944 \\
POSTWORDREAD & 4 & 13 & 18 & 15.75 & 2.217 \\
\hline
\end{tabular}

5.1.1 Peabody Picture Vocabulary Test (PPVT). A 2x2 ANOVA was conducted to look at the effect of time (pre and post) and group (treatment and control) on the PPVT. Results showed no main effect of time $[\mathrm{F}(1,6)=.0058, \mathrm{p}=.9414]$, no main effect of group $[\mathrm{F}(1,6)=2.89, \mathrm{p}=.139]$, and no interaction $[\mathrm{F}(1,6)=0938, \mathrm{p}=.7697]$.

5.1.2 Spelling. A 2x2 ANOVA was conducted to look at the effect of time (pre and post) and group (treatment and control) on spelling. Results showed no main effect of time $[\mathrm{F}(1,6)=1.84, \mathrm{p}=.2230]$, no main effect of group $[\mathrm{F}(1,6)=3.52, \mathrm{p}=.109]$, and no interaction $[\mathrm{F}(1,6)=4.15, \mathrm{p}=.0877]$.

5.1.3 Morphological Awareness (MA). A 2x2 ANOVA was conducted to examine the effect of time (pre and post) and group (treatment and control) on morphological awareness. Results showed no significant main effect of time $[\mathrm{F}(1,6)=4.15, \mathrm{p}=.0877]$, no significant main effect of group $[\mathrm{F}(1,6)=0.26$, $\mathrm{p}=.6278]$, and no significant interaction $[\mathrm{F}(1,6)=0.00, \mathrm{p}>.9999]$.

5.1.4 Word Reading. A 2x2 ANOVA was conducted to look at the effect of time (pre and post) and group (treatment and control) on word reading. Results showed a significant main effect of time $[\mathrm{F}(1,6)=9.52, \mathrm{p}=.0215]$, no main effect of group $[\mathrm{F}(1,6)=1.97, \mathrm{p}=.210]$, and no interaction $[\mathrm{F}(1,6)=2.38$, $\mathrm{p}=.1738]$.

The ANOVA analyses showed that it was only word reading that showed a significant improvement over time. However, it should be noted that this improvement was for both groups, not the treatment group alone. A larger sample size is needed to detect any treatment effect. Nevertheless, there is insufficient evidence to say that the treatment (game) does not work. A larger sample size is required to support any general claims. However, the descriptive data in Table 1 clearly shows an increase in the participants' scores across all measures (vocabulary, word reading, spelling, and MA) when comparing the pre-test to the post-test results. This increase in the mean average scores is worthy of attention since the ESL students played the game for a relatively short time frame (4 weeks). In addition, the main effect of time demonstrates that there is a significant change across time regardless of group (experimental vs. control). This is important to establish: though the game does not necessarily improve the assessment measures, it also does not hinder the learners' progress. 


\subsection{SALT analysis}

RQ2: What is the impact of in-game social interactions on ESL students' morphological awareness? To gauge the online L2 game's feasibility to improve ESL students' morphological awareness, we conducted a SALT analysis of the four ESL students' chat logs.

5.2.1 Total number of written utterances. There was a clear heterogeneity in the total number of written utterances of the four players. This could be a factor of their L2 expressive ability or their motivation to play the game. Another possible explanation for the distinct total number of written utterances per player was the type of social interactions between the NES and the ESL student. For example, NES participants were encouraged to ask their partners more questions about the images to generate more written L2 output from his partner. However, not all NES participants did so since some NES participants strictly focused on the task of finding the matching image, generating either monosyllabic responses (i.e., "Next") and consequently, less chat messages than other dyads. Refer to Tables 2 and 8 .

\begin{tabular}{|l||l||l|l|l|}
\hline \multicolumn{5}{|c|}{ Table 2. Total Number of Written Utterances } \\
\hline L2 Player & Min & Max & Mean & Std. Dev. \\
\hline ESL1 & 7 & 103 & 25.39 & 27.01 \\
ESL2 & 27 & 81 & 52 & 29.05 \\
ESL3 & 9 & 32 & 17.80 & 10.28 \\
ESL4 & 6 & 18 & 13.33 & 6.43 \\
\hline
\end{tabular}

5.2.2 Number of different words. The number of different or unique words was calculated on the basis of detecting unique words found in ESL students' chat logs as opposed to repeating the same words over and over again. This particular group of ESL students generated quite a range of unique words, from an average of 45 unique words (ESL3) to 123 unique words (ESL2) over a period of four weeks. Refer to Table 3.

\begin{tabular}{|l||l||l|l|l|}
\hline \multicolumn{5}{|c|}{ Table 3. Number of Different Words (NDW) } \\
\hline L2 Player & Min & Max & Mean & Std. Dev. \\
\hline ESL1 & 5 & 163 & 66.62 & 51.73 \\
ESL2 & 75 & 175 & 122.75 & 45.90 \\
ESL3 & 20 & 73 & 45.40 & 23.24 \\
ESL4 & 19 & 74 & 48 & 27.62 \\
\hline
\end{tabular}

5.2.3 Number of total words. The number of total words referred to all the words that ESL students wrote in their chat logs, including repeated words produced by each ESL student. ESL1 and ESL2 generated more chat messages, suggesting that they were more engaged in gameplay their the other two ESL students (ESL3 and ESL4). See Table 4.

\begin{tabular}{|l||l||l|l|l|}
\hline \multicolumn{5}{|c|}{ Table 4. Number of Total Words (NTW) } \\
\hline L2 Player & Min & Max & Mean & Std. Dev. \\
\hline ESL1 & 12 & 499 & 144.62 & 151.38 \\
ESL2 & 107 & 404 & 267.25 & 158.54 \\
ESL3 & 30 & 165 & 90 & 68.33 \\
ESL4 & 23 & 150 & 89 & 63.65 \\
\hline
\end{tabular}

5.2.4 Omission of bound morphemes. Omission of bound morphemes refers to omitting grammatical markers such as the suffix -ed for the past tense. Participants ESL1 and ESL2 omit more bound morphemes than ESL3 and ESL4. Of course, because ESL1 and ESL2 generated more chat messages, they appears to make more grammatical mistakes than the other two ESL students, thus indicating specific areas of improvement. Though only a few errors were found in the four-week language 
sample, these results suggest that ESL1 and ESL2 would benefit from explicit morphological instruction [45] that emphasizes grammatical suffixes and prefixes (morphemes) to enhance their literacy skills, including spelling, vocabulary acquisition, and reading comprehension. Refer to Table 5.

\begin{tabular}{|l||l||l|l|l|}
\hline \multicolumn{5}{|c|}{ Table 5. Omission of Bound Morphemes (OmitBD) } \\
\hline L2 Player & Min & Max & Mean & Std. Dev. \\
\hline ESL1 & 0 & 7 & 2.39 & 2.60 \\
ESL2 & 0 & 9 & 4 & 3.74 \\
ESL3 & 0 & 1 & 0.20 & 0.45 \\
ESL4 & 0 & 1 & 0.67 & 0.58 \\
\hline
\end{tabular}

5.2.5 Total of correct bound morphemes. This refers to the correct bound morphemes (prefixes and suffixes) in one's language sample. The use of bound morpheme increases the complexity of the word and makes it a polymorphemic word. ESL1 and ESL2 demonstrate the use of correct bound morphemes in their chat logs, suggesting a somewhat higher degree of proficiency in written English literacy skills than ESL3 or ESL4. See Table 6.

\begin{tabular}{|l||l||l|l|l|}
\hline \multicolumn{5}{|c|}{ Table 6. Total Number of Correct Bound Morphemes (BDMorphTot) } \\
\hline L2 Player & Min & Max & Mean & Std. Dev. \\
\hline ESL1 & 0 & 31 & 9.62 & 11.20 \\
ESL2 & 7 & 26 & 14.50 & 8.10 \\
ESL3 & 0 & 14 & 6.20 & 5.45 \\
ESL4 & 2 & 8 & 5.33 & 3.06 \\
\hline
\end{tabular}

Finally, the Pearson correlations between these variables also indicated that this game provided an opportunity to significantly enhance L2 students' English proficiency and literacy skills. The number of unique words (NDW) was significantly correlated with the usage of correctly bound morphemes (BDMorphTot), the total number of words (NTW) and the number of omitted bound morphemes (OmitBD) found in ESL students' chat logs. This finding suggested that ESL students generated a larger variety of unique vocabulary words, possibly because of their increased MA skills, and generated a higher total of English words in their written dialogue. In comparison, the correct usage of bound morphemes (BDMorphTot) was significantly correlated with the total number of words found in ESL students' chat logs, indicating that ESL students produced a higher count of words that included root words in their conversations with their NES partners. The number of total words (NTW) was significantly correlated with the number of omitted bound morphemes, again indicating that ESL students who generated a higher count of words in their chat logs, also generated a higher number of grammatically incorrect English words (words missing correct prefixes or suffixes). The combination of findings clearly suggested that the two-player online game has the potential to positively impact ESL students' MA. See Table 7.

\begin{tabular}{|l||l||l|l|l|}
\hline \multicolumn{5}{|c|}{ Table 7. Pearson Correlation of Morphological Measures } \\
\hline & NDW & BDMorphTot & NTW & OmitBD \\
\hline NDW & 1 & & & \\
BDMorphTot & $.845^{* *}$ & 1 & & \\
NTW & $.965^{* *}$ & $.880^{* *}$ & 1 & \\
OmitBD & $.696^{* *}$ & .396 & $.619^{* *}$ & 1 \\
\hline
\end{tabular}

\subsection{The Quality of Social Interactions between Players}

Research Question 3 (How well does the online game facilitate meaningful social interactions between NES and ESL students?) gauged the game's ability to foster social interactions between ESL students and NES as part of the gameplay experience. To gauge ESL students' willingness to communicate 
(WTC) with their NES partners, we monitored the amount of time each dyad spent playing the game, the amount of chat messages generated per individual and the percentage of input each player contributed to the paired interaction. See Table 8 below. Overall, dyads 1, 2 and 3 engaged in more chat-based interactions than dyad 4 even though the time spent playing the game varied for each dyad. In all four dyads, the ESL players generated more chat messages $(\mathrm{ESL} 1=443$, ESL2 = 149 , ESL3 $=316$, and ESL4 $=64)$ than their NES partners. However, the percentage of input for the chat-based interactions revealed different social dynamics for some of the dyads. For example, the percentage of input for dyads 1 and 2 showed that the conversational exchange was more evenly distributed between partners. For dyad 4, ESL4 generated almost twice as many chat messages than his partner in one short session (approximately 21 minutes) of gameplay, suggesting that he was initially motivated to engage in conversation with a NES. However, NES4 generated the least number of chat messages (34), choosing to withdraw from the game study after only one gaming session. Overall, dyads 1, 2 and 3 spent more time playing the game with dyad 1 spending the most time (more than 3.5 hours). The stark contrast between dyad 4 and the other three dyads required a closer look at what happened between distinctly linguistically matched players.

Because playtesting is a crucial phase of game design, one in which designers intentionally elicit players' feedback about their gameplay experiences, we elicited feedback during the focus group discussion (per their request) of ESL students and the semi-structured interviews with their NES partners. (NES4 did not participate in the post-game interview.) This allowed us to probe players' reflections of their gameplay experiences to understand which factors influenced their WTC and how this might have contributed to their L2 language and literacy skills.

\begin{tabular}{|l||l||l|l|l|}
\hline \multicolumn{5}{|c|}{ Table 8. Player Experience Data } \\
\hline \multirow{2}{*}{ Dyad } & $\begin{array}{l}\text { Native } \\
\text { Language }\end{array}$ & $\begin{array}{l}\text { Level of } \\
\text { English } \\
\text { Proficiency }\end{array}$ & $\begin{array}{l}\text { Hrs:Mins:Secs } \\
\text { Spent Playing } \\
\text { Game }\end{array}$ & $\begin{array}{l}\text { Number \& } \\
\text { \% of Chat } \\
\text { Msgs }\end{array}$ \\
\hline \multirow{3}{*}{2} & Vietnamese & Intermediate & $4: 15: 58$ & $443(58 \%)$ \\
& English & N/A & $3: 52: 57$ & $315(42 \%)$ \\
& Arabic & Intermediate & $2: 00: 59$ & $149(55 \%)$ \\
& English & N/A & $2: 00: 59$ & $121(45 \%)$ \\
& Arabic & Intermediate & $1: 45: 37$ & $316(62 \%)$ \\
& English & N/A & $1: 45: 37$ & $197(38 \%)$ \\
& Arabic & Intermediate & $0: 20: 45$ & $64(65 \%)$ \\
& English & N/A & $0: 20: 45$ & $34(35 \%)$ \\
\hline
\end{tabular}

5.3.1 Chat-based interactions contributed towards ESL students' vocabulary acquisition and their $M A$. ESL students talked about how interactions with their native English speaking partners helped them learn new English vocabulary words, appreciating the game concept of describing topical images to introduce L2 vocabulary words. During the focus group discussion, ESL3 shared her experience.

\section{ESL3: I didn't know the word. For example, I didn't know the word...but I still can describe from my panel, like I am in a room with a bottle - a bottle that we can put the flower...I don't remember the vocabulary word, so I like that even [if] I don't remember the vocab -the vocabulary, like the name of like for example, vase, I will try...I need to use as much as I can about my English to describe for my partner.}

In this example, ESL3 did not know the English vocabulary word vase but applied her knowledge of the English language to describe what she saw in the room while her partner (NES3) provided the correct word of the object in the chat window, an example of the L2 vocabulary learning strategy 


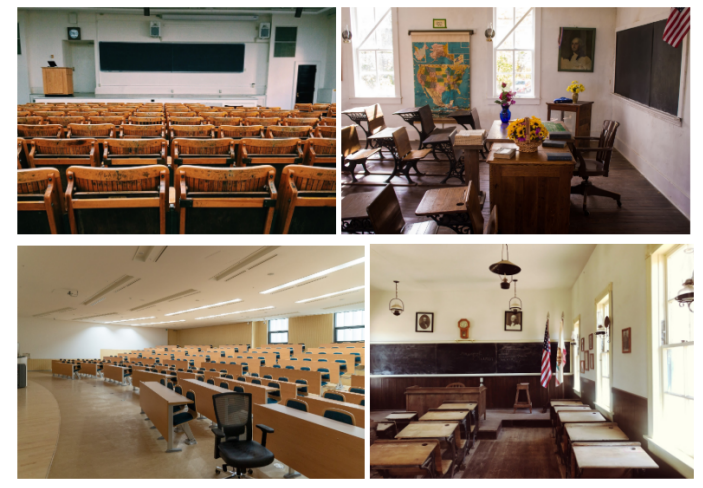

Fig. 3. Similar images of four different classrooms, each containing a different configuration of desks.

of working with others [82]. When asked about this experience during the interview, NES3 admitted that he was motivated to help his game partner learn new vocabulary words and took advantage of opportunities to do so.

NES3: You have to have more discussion to differentiate them [...] And it actually helped too, because there were some times where I would explain something and she's like I'm not sure what that is, so I'd have to explain it to her a little bit more or vice versa.

NES3's ability to provide the correct vocabulary word at just the right time exemplified realtime human scaffolding which was possible because of how the topical scenes supported the combination of visual grounding with conversational grounding, a process that typically occurs in social interactions between native and non-native speakers [5, 38, 39, 50, 81]. ESL3 also talked about the difficulty in describing two images that had similar yet distinguishing details.

ESL3: Sometimes you think that it's easy [...] if this picture is easy, if you're always the one who describe it, but if [...] you are the one who has like different room, you will know it is not easy, because all the rooms look like same [...] I tell him it has like a red table, and he say I have like two or three rooms with a red table, so you have to describe more.

This highlights the usefulness of visual context in helping players to notice the nuanced details of different topical images that are relevant for using the appropriate English vocabulary words to describe these details to their partner (e.g., Figure 3).

In addition, the game provided an opportunity to stimulate students' MA using highly similar images where the player had to notice specific details to distinguish one image from another. (See Figure 3 of the four different physical configuration of classrooms.) Paying attention to the nuanced details of images pointed to opportunities for ESL students to use bound morphemes when describing specific objects to their partners via chat. For example, ESL1 wrote "cherry tomatoes," indicative of the plural form of tomato which requires the suffix -es, to describe the ingredients displayed on a kitchen counter in her chat window. This particular chat-based message demonstrated how the combination of topical images (visual grounding) and chat-based interactions (conversational grounding) can be used to promote MA and spelling accuracy. Both the ESL students and their NES partners appreciated the more nuanced images as indicative of the level of difficulty and thought that it contributed to a more challenging and fun player experience.

5.3.2 The game objective motivated ESL students' and NES' willingness to communicate. The game objective of finding matching images motivated ESL players' WTC with their respective partners 
and consequently, influenced the number of ESL students' generated chat messages and the amount of time spent playing the game. NES2 talked about managing scheduling conflicts to squeeze in some time to play the game with his partner.

NES2: It was kind of hard [...] we'd make dates, but we'd never stick to the dates we set [...] kind of spontaneous [...] I always [...] let him choose the days [...] it seemed like he had a busier schedule than I did [...] most of the times [...] I could do it [...] I really don't do much other than just work and school [...] we would play until we'd completed like four games.

Dyad 2 ran into scheduling conflicts since the real issue was finding a convenient time that worked for both players. ESL2 suggested playing the game on the weekends, but his other responsibilities made it difficult for them to stick to a regularly scheduled time even on the weekends. When asked if he had attempted to negotiate a different date and time to play the game with his partner, NES2 shared that he wanted his partner to choose the time, so he intentionally accommodated his ESL partner's schedule. Maintaining some degree of flexibility enabled dyad 2 to play the game regularly for four consecutive weeks, but they generated fewer chat messages than dyads 1 and 3 . Because of time constraints, their chat-based interactions were focused strictly on the task of finding the matching images and included more monosyllabic interactions (e.g., "Next") as opposed to spending time getting to know one another. Consequently, their chat-based interactions resembled casual or episodic gameplay [11], and despite their brevity, seemed to have a positive influence on ESL2's English language and literacy skills. (Refer to Table 1.) This suggested that even episodic gameplay was meaningful in the context of accomplishing the game objective and contributing towards ESL players' WTC.

In contrast, dyad 4 generated the least number of chat messages. Though we did not interview NES4, ESL4 explained that his English speaking partner had difficulty with internet connectivity which precluded him from playing the game. As such, they were not successful in achieving the game objective which led to frustration and eventually discouragement in participating in the game study. ESL4 shared what his partner told him via an email exchange.

ESL4: My partner [...] because I chose like Friday [...] he told me, "It's not good for me." [...] and he sent an e-mail for us to change the date and and I change it. And I told him I'm okay [...] I think the problem is the network. It was like weak [...] he was like trying to play with me and he was like busy, because the weekend is not good for him.

We acknowledge that internet connectivity issues, well beyond our control, would definitely have a negative impact on ESL's students' WTC. Unpacking this second hand account of what transpired between ESL4 and NES4, we recognize that dyad 4 also had schedule conflicts like dyad 2 and attempted to handle them in a similar manner. Though ESL4 tried to accommodate NES4's schedule, NES4 had issues with logging into the game, and instead of asking for assistance, NES4 decided participation in the game study was not feasible. Interestingly enough, NES4 did not communicate his decision to the research team when he chose to abandon his partner. The inability to log into the game prevented this dyad from working towards completing the game objectives, and this in turn discouraged ESL4 from communicating with his partner.

\subsubsection{In-game and out-of-game social interactions contributed to ESL students' willingness to com-} municate (WTC). Both NES and ESL students in dyads 1 and 3 indicated that they had fun communicating with their partners during gameplay, but also talked about things not related to the game. Additionally, dyads 1 and 3 used the \#GroupMe application to engage in conversations before and after the scheduled game session.

NES3: We would talk a lot, so we'd get to know each other [...] especially since we're [...] very different, like where we came from [...] we could share a lot of experiences [...] I shared 
[...] some of my music and so did she [...] like kind of reciprocating. It was really nice [...] I talked about how [...] I loved music [...] I texted her a YouTube link for like a [music] piece [...] the next time we met, she showed me some of instruments [where] she came from [...] this really cool looking guitar and drums [...] we were sharing that experience.

In this scenario, ESL3 and her NES partner (dyad 3) used the \#GroupMe application to exchange videos of their favorite musical artists and talk about other non-game related topics outside of the two-player online game. The NES partner shared intimate details of his life and expressed genuine interest in getting to know his game partner as well. NES3 looked forward to communicating with ESL3 and eventually perceived his game partner to be a friend. As a result of continuous gameplay and out-of-game conversations, dyad 3 established a rapport that contributed to both players' WTC with one another. Consequently, ESL3 generated the second highest number of chat messages (281) which suggested the the combination of in-game and out-of-game social interactions created a positive gameplay experience for both players.

In comparison, ESL1 (from dyad 1) experienced problems trying to connect with her originally assigned NES partner. As a result, we assigned her a new NES partner (NES1) who was more responsive during gameplay. ESL1 compared her second NES partner to the first one.

ESL1: He's so nice [...] we talk before playing [...] I really enjoy it with him. The first one I didn't [...] my problem was he log out without telling me [...] [NES1] was different [...] he would ask how is your day [...] we laugh [...] we make same joke in the game and things.

The first NES who was assigned as ESL1's partner exhibited rude behavior by logging out of the game without telling her that he was leaving. After multiple attempts to communicate, ESL1 eventually figured out that he had left the game without telling her. This created a negative gameplay experience, so we quickly assigned her a new NES partner. In comparison, her second partner, NES1, treated her like a human being, taking the time to get to know her while engaging in small talk to forge a meaningful connection. Her second NES partner's friendly behavior increased her WTC in the L2, which consequently produced the longest play period (4 hours and 16 minutes) and generated the most chat messages (443) with fewer errors than the other 3 ESL students. These kinds of social interactions, characterized as friendly and attentive, suggest that it is more so the native speakers' attitudes that influence L2 players' WTC and increase the quantity of written L2 output than the game. Because the chat-based interface hides players' real identity, the game does increase the likelihood that L2 students will take the risk of engaging in social interactions with strangers, even if some strangers are not as friendly.

When asked why they decided to participate in the game study, all three NES participants indicated that they were motivated to help others and saw the game study as an opportunity to do so. NES3 captured this sentiment in the quote below:

It appealed to me because I like playing games. I hadn't played a video game in a long time, and the concept of being able to help a non-native speaking foreigner help better understand English was something that combined with the funness of the game I thought was a meaningful thing to do during the semester.

Even NES2 liked the game concept and was initially motivated to participate in the game study because he wanted to provide feedback to improve the game prototype. However, due to scheduling conflicts with his ESL partner, dyad 2 only played the game for short bursts of time on the weekend. As is typical of episodic gameplay [11], they would quickly identify matching images after four rounds before ending the gaming session. NES2 described how the chat-based interactions evolved over time. 
NES2: When we first started, it wasn't good, but I feel like he opened up more [...] so we actually started communicating more, and he started asking more questions [...] he realized how [...] I was replying to some [...] if I was the person looking for a photo I would be like, "I found it. Now what do you see?" Before, he would find it and just not say any[thing] [...] keeping those replies going just made the conversation keep going [...] he started like giving me more elaborate details.

This reflection showed that though the in-game social interactions were part of the gameplay experience, the NES played a critical role in encouraging more hesitant ESL students to engage in meaningful chat-based interactions. For example, because NES2 asked more questions which required written responses, ESL2 began to share more details about the images and responded in a similar manner by asking questions of his own when searching when searching for the matching image and providing more details of what he saw. Hence, ESL2 modeled his partner's behavior, sharing "more elaborate details" when describing the images, a positive influence in increasing his WTC. In comparison, dyad 4 generated the least amount of chat messages (98) with ESL4 generating twice as many messages as his English speaking partner. When NES4 abruptly withdrew from the study after only one gaming session because of reportedly limited availability and internet connectivity issues, this caused confusion for ESL4 who was unsure as to why NES4 chose to no longer participate in the study. He might have even partially blamed himself for his partner's decision to not participate. Consequently, ESL4 quietly withdrew from the game study as well. This suggested that although the game requires social interactions between players, the native English speakers' attitudes became an influential factor in ESL students' behaviors inside and outside the game and can have negative impacts for long-term gameplay. This was evident in the reflections of all four ESL students' gameplay experiences.

\section{DISCUSSION}

The findings demonstrate the potential of this two-player online game to increase ESL students' language and literacy skills as a mechanism for engaging in social interactions with native English speakers to accomplish the game objective of finding matching images. While this is promising in the early stages of prototyping, we discuss the implications of using socially interactive games to facilitate L2 students' language, literacy, and WTC.

\subsection{Specific elements of gameplay were beneficial for L2 learning}

In the context of designing socially interactive games to increase L2 students' proficiency in the target language, certain game elements played a strategic role.

6.1.1 ESL students were more frequently positioned as Player 1. Since the ESL students were motivated to play the game to help increase their English proficiency and literacy, we modified the game to more frequently position ESL students as being Player 1, forcing them to generate more chat messages to describe the details in the pictures. We found this to be beneficial in increasing the number and quality of chat messages ESL students produced. For example, when ESL students were Player 2, the one who was searching through a series of images, the ESL students rarely responded to their partners' chat messages since they were busy pressing the Next button and only reading what their partners typed in the chat window. Consequently, they generated more monosyllabic chat messages (e.g., "Next") and their NES partner dominated the conversation. However, when ESL students were Player 1, we saw an increase in the number and quality of chat messages they generated which contributed to their ability to drive the conversation. Thus, it was important that the game be designed to ensure that both players have equal opportunities (take turns) to describe the topical images since they facilitated L2 students' language and literacy skills and WTC. 
6.1.2 The game attempted to bridge L2 students' communicative capabilities with their L2 vocabulary acquisition. Overall, the ESL students had a positive perception of the game prototype and appreciated the opportunity to use their prior knowledge of the English language to describe a particular object in a scene, even if they did not know the correct vocabulary word. Because the game was designed to inherently support the learning strategy of working with others to acquire knowledge of new vocabulary words [82], the game provided plenty of opportunities for the ESL students to practice communicating with NES players, one of the primary benefits of gameplay. This spoke to the game's feasibility to increase ESL students' WTC. More importantly, the social interactions with NES and the visual context served as a bridge between L2 students' current communicative capabilities and the desired knowledge of new L2 vocabulary.

6.1.3 Topical images supported certain aspects of L2 literacy. We selected topical images on the basis of two reasons. First, because we could not control the words players generated in their chat messages, we intentionally used more than 700 images to represent different topics such as food, places to go, games, classrooms, bedrooms, etc. to expose ESL students to a variety of English vocabulary words. The topical images were randomly selected for each game session, allowing ESL students to revisit previously viewed images as a pedagogical strategy for recalling newly introduced English vocabulary words. While the repetition of images was perceived as being annoyingly redundant at times, it encouraged ESL students to use new English words in their chat messages. Second, we chose highly similar images to force students to think about the specific details as the means for distinguishing one image from another. As previously mentioned in section 5, highly similar images required more chat messages since Player 1 needed to describe specific details. Such nuances were useful for drawing attention to English vocabulary, word reading accuracy and MA.

However, the game fell short of supporting certain aspects of MA. For example, though we included images of people performing different activities (e.g., chopping, eating, playing sports, etc.), it was very difficult for the topical images to convey the past tense of verbs. Thus, the ESL students used the present tense when describing images of activities. In addition, writing responses to chat messages was not equivalent to composing sentences, paragraphs or essays. Chat-based messages were a poor substitute for practicing L2 written grammatical skills. Furthermore, the abbreviated style of writing chat messages can inhibit L2 students' development of spelling accuracy.

\subsection{The game provided useful information to assess L2 vocabulary choice and spelling}

L2 teachers can utilize this game to generate written output (chat logs) as a mechanism to evaluate L2 students' literacy skills over time. For example, the first few game sessions would provide a baseline of an individual student's L2 literacy skills. After several sessions of gameplay, the L2 teacher can check the total number of words and the total number of different words to determine if the L2 student is using new vocabulary words in her chat logs. Additionally, the teacher can check the L2 student's chat logs to see if there is proper use of morphemes, including an increase in bound morphemes and a decrease in omitted morphemes which indicate that the L2 student has improved her MA. For the category of omitted morphemes, the instructor can look at the L2 student's chat logs and prescribe a customized lesson plan to help that L2 student work on acquiring specific English vocabulary words and their corresponding prefixes and suffixes to assist the student with improving her morphological accuracy, spelling, and lexical inferencing (i.e., enhanced meaning of words). Likewise, the teacher can advise the student to spend more time playing the game, recommending topical images for special attention, as a supplementary pedagogical strategy to classroom instruction. The game could use color to highlight the base of a complex word to draw English learners' attention to the base of a complex/polymorphemic word which could in turn 


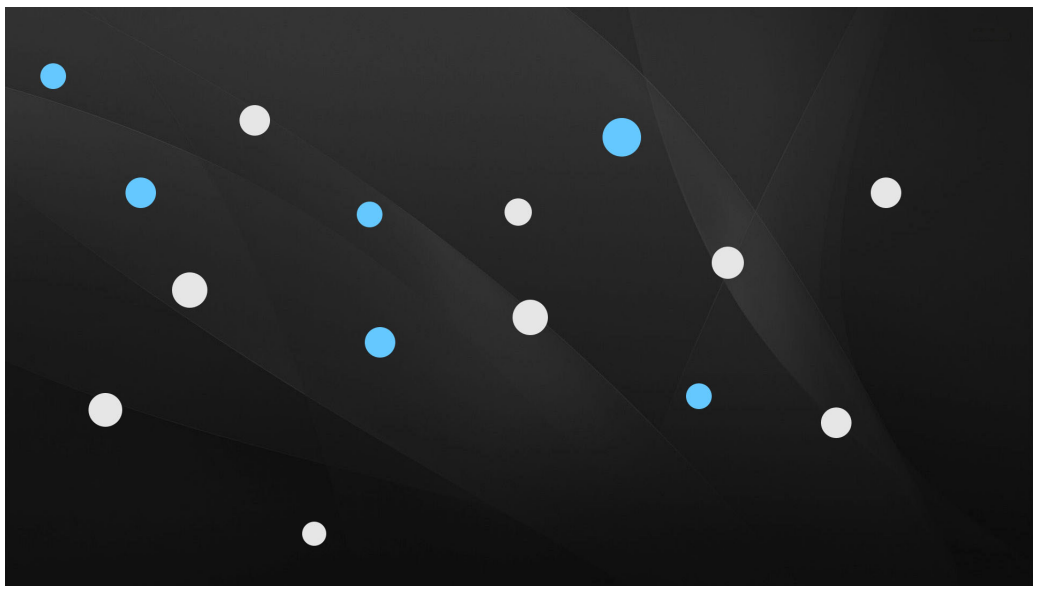

Fig. 4. Mockup of linguistically distinct players waiting in the lobby area of the game.

enhance morphological knowledge (morphological analysis and morphological decoding), word recognition and reading comprehension.

\subsection{ESL Students had design ideas for better accommodating L2 players' experiences}

As a result of participating the focus group discussion to reflect on their gameplay experiences, the ESL students had specific suggestions for improving the gameplay experience.

6.3.1 Visualizing players' status. ESL students discussed the need to have information about their partner's status during gameplay to better facilitate positive interactions with their partners. Because this 2D game did not provide an immersive virtual environment for native and non-native speakers to interact with one another, visual information was critical for encouraging players to interact with each other. For example, since players did not have visual representation (i.e., avatars) as part of the gameplay experience, the ESL students did not know when their partner was still online, in the midst of composing a chat message, or had left the game. Visualizing players' status would provide useful information to assist players with managing their time rather than waiting in limbo and hoping someone is available to play the game.

One probable solution is the concept of a waiting area to visualize players' availability and linguistic capabilities once players log into the game. We demonstrate this concept in Figure 3. In the game interface mockup (Figure 3), the color blue represents NES and the color white represents ESL students. Visualizing players' availability along with their linguistic capabilities gives players a quick sense of who is available to play the game while encouraging ESL players to interact with NES players to practice their written English conversational skills. As another mechanism for practicing L2 conversational skills, the game would automatically pair linguistically distinct players, facilitating interpersonal communication between native and non-native speakers. Likewise, automatically displaying player status on the screen (e.g., "typing" in the chat window) would provide useful information to help players adjust their behavior accordingly (e.g., being patient as they wait for a response). However, visualizing player status on the screen does not eliminate impolite or rude behavior nor does it address the negative emotional impact such behavior may have on players. 
6.3.2 Additional built-in scaffolds for L2 learning. The ESL student who generated the second highest number of chat messages offered a suggestion for a built-in scaffold to support vocabulary acquisition and MA - a one-minute review of newly introduced English vocabulary preferably composed of multiple morphemes as a primer for the topical images. This primer would help them to focus their attention on specific objects individually, recall these objects in the context of details of a scene, and attempt to use the appropriate vocabulary word and its correct constituent morphemes in their conversational interactions when describing the scene to their partner. Because players were primarily responsible for describing the details of the pictures, the ESL students also suggested occasionally displaying potential vocabulary words on the screen as hints if players became stuck on a picture after a considerable amount of time has passed. We thought this was a good idea and decided to show a list of potential vocabulary words in the chat window when a game session (a set images of a specific topic) begins and when one player is unable to find the matching image after two minutes have passed. Refer to Figure 4. Another suggestion was to include a dictionary with the definition, visual image and pronunciation of English vocabulary words as a Help Option during gameplay. All of these suggestions can be easily implemented as built-in scaffolds in future design iterations of the game.

6.3.3 More support for learner autonomy. The ESL students thought that it is equally important to have a sense of control or autonomy of the gameplay experience. This was not unusual as research shows that most players appreciate autonomy or a customized player experience [13]. For example, the game was intentionally designed to randomly select topics, sometimes displaying pictures that players have already seen and matched in a previous gaming session. As game designers, we used the random selection of picture topics to create an element of fun and challenge during gameplay. However, the ESL students requested the option to select topics since their primary objective was to increase their English vocabulary and literacy skills. Giving players the option of choosing the topic in advance would help L2 students to think about related vocabulary words that can be used to describe objects in the scenes. Learner autonomy contributes to a positive gameplay experience and should be one of the design goals for accommodating L2 students' written literacy skills.

\section{LIMITATIONS OF STUDY}

Despite the rich qualitative data that was obtained, 4 participants represents a very small sample size for statistical analysis. Future work involves recruiting a much larger sample size to evaluate the game's ability to increase ESL students' L2 literacy skills. Additionally, conducting a series of pilot studies that only test one or two game design specifications in a short time frame will help us to identify opportunities to better scaffold L2 literacy, creating a positive gameplay experience for ESL students. If we have more chat logs/output from each participant in addition to more participants, then we can compare the language output for each participant across time (e.g., playtest sessions $1 \& 2$ early in the game compared to playtest sessions $13 \& 15$ later in the game) to determine if L2 students are improving their MA as a result of repeated gameplay. Having a significantly larger sample size would enable a more robust quantitative data analysis to look into predictors of literacy of L2 learners. A more critical selection of images to support present versus past tense and the identification of words that belong to the same morphological family will improve the game's potential to enhance L2 students' MA. Another critical issue is motivating NES to participate in a longitudinal study. Providing increased compensation as a reward for continued participation in the game study may contribute to the increased retention of both ESL and NES players. Also, having a face-to-face kickoff meeting as part of the game study can contribute to building better rapport between players. Finally, we did not gauge ESL students' emotional state or level of engagement 
during gameplay, inviting further investigation about their impact on ESL students' L2 literacy skills. These limitations will inform future work.

\section{CONCLUSION}

In summary, we developed a prototype of a socially interactive game that provided an opportunity for four ESL students to interact with four NES and reflect on their morphological awareness as part of the gameplay experience. The game promotes situated L2 learning in that two linguistically paired players (1 ESL and 1 NES) have visual access to the same images and can engage in a conversation about the details of those images, allowing L2 students to utilize L2 vocabulary to talk about concrete objects instead of abstract concepts which may be difficult for L2 students to grasp. Equally important, the online two-player game allowed players a certain degree of anonymity, providing L2 learners who may suffer from language anxiety a judgement-free virtual environment to practice their conversational skills with native speakers in the target language.

The impact of gameplay on ESL students' L2 literacy skills was determined by pre- and postassessments of English literacy (vocabulary, spelling, MA, and word reading). Results suggested that the game has the potential to increase ESL students' word reading accuracy, an important indicator of English proficiency. The descriptive data (Table 1) clearly shows the increase in the participants' scores across all measures (vocabulary, word reading, spelling, and MA) when comparing the preto the post-test results. This increase in the mean average scores is remarkable considering the relatively short duration of the game and the few participants $(\mathrm{N}=4)$ in the current study. Such promising results should encourage future researchers to conduct more studies. Furthermore, a SALT analysis of ESL students' chat logs (> 900 chat messages), including the total number of chat messages generated, total number of words, the total number of unique words, the total number of correct morphemes and any grammatical errors (omission of bound morphemes) indicated the game's potential to enhance students' MA, an important indicator of students' comprehensive literacy skills in the target language. The findings from this game study shed light on the game's potential to sufficiently engage ESL students in chat-based conversations with NES while generating sufficient written output which can be used to establish a baseline of ESL students' MA. The chatbased conversational game requires L2 players to respond to their partner in a timely manner, which is crucial for developing vocabulary and conversational fluency in the target language. Finally, participants' feedback about their gameplay experiences indicated the potential of the L2 game to sustain long-term engagement that will enable ESL students to continuously practice their L2 communication skills and further develop their English literacy skills.

\section{ACKNOWLEDGEMENTS}

This research is generously supported by the National Science Foundation \#1757397 and the Florida State University College of Communication \& Information \#NC-2018-001.

\section{REFERENCES}

[1] Laura K. Allen, Scott A. Crossley, Erica L. Snow, and Danielle S. McNamara. 2014. L2 writing practice: Game enjoyment as a key to engagement. Language Learning \& Technology 18, 2 (2014), 124-150. http://llt.msu.edu/issues/june2014/ varneretal.pdf

[2] Christopher Brumfit. 1984. Communicative Methodology in Language Teaching. Cambridge: Cambridge University.

[3] Jose R. Calvo-Ferrer. 2017. Educational games as stand-alone learning tools and their motivational effect on L2 vocabulary acquisition and perceived learning gains. British fournal of Educational Technology 48, 2 (2017), 264-278 doi:10.1111/bjet.12387

[4] Michael Canale. 1983. From communicative competence to communicative language pedagogy. In f.C. Richards and R.W. Schmidt (Eds.) Language and Communication (1983), 2-27. 
[5] Michale Canale and Merrill Swain. 1980. Theoretical Bases of Communicative Approaches to Second Language Teaching and Testing. Applied Linguistics 1 (1980), 1-47.

[6] Joanne F. Carlisle. 1995. Morphological awareness and early reading achievement. (1995), 189-209.

[7] Joanne F. Carlisle. 2000. Awareness of the structure and meaning of morphologically complex words: Impact on reading. Reading and Writing: An Interdisciplinary fournal 12 (2000), 169-190. https://doi.org/doi:10.1023/A:1008131926604

[8] Joanne F. Carlisle and Devin M. Kearns. 2017. Learning to read morphologically complex words. , 191-214 pages.

[9] Ching Chang, Ju-Ling Shih, and Chih-Kai Chang. 2017. A mobile instructional pervasive game method for language learning. Universal Access in the Information Society 16, 3 (2017), 653-665.

[10] Meng-Hua Chen, Wen-Ta Tseng, and Tsung-Yuan Hsiao. 2016. The effectiveness of digital gamebased vocabulary learning: A framework-based view of meta-analysis: The effectiveness of DGBL. British fournal of Educational Technology 49, 1 (2016), 1-9.

[11] Shira Chess. 2017. Ready player two : women gamers and designed identity. Feminist Media Studies (2017). https: //doi.org/10.1080/14680777.2018.1498142

[12] Alice Chik. 2014. Digital Gaming and Language Learning: autonomy and community. Language Learning \& Technology 18, 2 (2014), 85-100.

[13] Karina Collentine. 2012. Learner autonomy in a task-based 3D world and production. Language Learning \& Technology 15, 3 (2012), 50-67.

[14] Frederik Cornillie, Geraldine Clarebout, and Piet Desmet. 2012. Between Learning and Playing: Exploring learners' perceptions of corrective feedback in an immersive game for English pragmatics. ReCALL 24, 3 (2012), 257-278.

[15] Frederik Cornillie, Kris Van den Branden, and Piet Desmet. 2015. From language play to linguistic form and back again: Lessons from an experimental study for the design of task-based language practice supported by games. (214-222 pages.

[16] Frederik Cornillie, Wim Van Den Noortgate, Kris Van den Branden, and Piet Desmet. 2017. Examining focused L2 practice: From in vitro to in vivo. Language Learning \& Technology 21, 1 (2017), 121-145. http://llt.msu.edu/issues/ february2017/cornillieetal.pdf

[17] Amy C. Crosson, Margaret G. Mckeown, Puiwa Lei, Hui Zhao, Xinyue Li, Kelly Patrick, Kathleen Brown, and Yaqi Shen. 2020. Morphological analysis skill and academic vocabulary knowledge are malleable through intervention and may contribute to reading comprehension for multilingual adolescents. Fournal of Research in Reading 44, 3 (2020), 1-21. 10.1111/1467-9817.12323

[18] Gabriel Culbertson, Erik Andersen, Walker White, Daniel Zhang, and Malte Jung. 2016. Crystallize: An Immersive, Collaborative Game for Second Language Learning. In Computer Supported Collaborative Work CSCW'16 (FEBRUARY 27 - MARCH2, 2016). 636-647.

[19] Gabriel Culbertson, Shiyu Wang, Malte Jung, and Erik Andersen. 2016. Social Situational Language Learning through an Online 3D Game. In Proceedings of the 2016 CHI Conference on Human Factors in Computing Systems (May $07-12$, 2016). 957-968.

[20] H.S. Deacon and John R. Kirby. 2004. Morphological awareness: Just "more phonological?" The roles of morphological and phonological awareness in reading development. Applied Psycholinguistics 25 (2004), 223-238. https://doi.org/doi: 10.1017.S0124716404001117

[21] S. Hélène Deacon, Michael J. Kieffer, and Annie Laroche. 2014. The Relation Between Morphological Awareness and Reading Comprehension: Evidence From Mediation and Longitudinal Models. Scientific Studies of Reading 18, 6 (1 11 2014), 432-451. https://doi.org/10.1080/10888438.2014.926907

[22] Zoltan Dornyei and Ema Ushioda. 2009. Motivation, Language Identity and the L2 Self. Multilingual Matters.

[23] Nicolas Ducheneaut, Robert J. Moore, and Eric Nickell. 2007. Virtual "Third Places": A Case Study of Sociability in Massively Multiplayer Games. Comput. Supported Coop. Work 16, 1-2 (April 2007), 129-166. https://doi.org/10.1007/ s10606-007-9041-8

[24] Lloyd Dunn and Leota Dunn. 1997. Peabody Picture Vocabulary Test (3rd ed.).

[25] Mohsen Ebrahimzadeh and Sepideh Alavi. 2016. THE EFFECT OF DIGITAL VIDEO GAMES ON EFL STUDENTS' LANGUAGE LEARNING MOTIVATION. Teaching English with Technology 17, 2 (2016), 87-112.

[26] Stephen J. Franciosi, Junichi Yagi, Yuuki Tomoshige, and Suying Ye. 2016. The effect of a simple simulation game on long-term vocabulary retention. CALICO Journal 33, 3 (2016), 355-379.

[27] Tracy Fullerton. 2019. Game Design Workshop: A playcentric approach to creating innovative games (4th edition). A K Peters/CRC Press.

[28] Nada Gamlo. 2019. The Impact of Mobile Game-Based Language Learning Apps on EFL Learners' Motivation. English Language Teaching 12, 4 (2019), 49-56.

[29] Robert Godwin-Jones. 2014. Games in language learning: opportunities and challenges. Language Learning and Technology 18, 2 (2014), 9-19. 
[30] Amanda P. Goodwin and Soyeon Ahn. 2013. A Meta-Analysis of Morphological Interventions in English: Effects on Literacy Outcomes for School-Age Children. Scientific Studies of Reading 17, 4 (2013), 257-285. https://doi.org/10. 1080/10888438.2012.689791 arXiv:https://doi.org/10.1080/10888438.2012.689791

[31] Amanda P. Goodwin, A. Corinne Huggins, Maria S. Carlo, Diane August, and Margarita Calderon. 2013. Minding morphology: How morphological awareness relates to reading for English language learners. Reading and Writing 26 (2013), 1387-1415. https://doi.org/10.1007/s11145-012-9412-5

[32] RAND Reading Study Group. 2002. Reading for understanding: Toward an R\&D program in reading comprehension.

[33] Craig D. Howard and Jaewoo Do. 2017. L2 (Im) politeness in the Synchronous Chat of Elementary School Learners. Teaching English with Technology 17, 1 (2017), 17-45.

[34] Hsui-Ting Hung, Jo-Ling Chang, and Hui-Chin Yeh. 2016. A review of trends in digital game-based language learning research. In In 7. Spector and C. Tsai and D. Sampson and R. Kinshuk, and N. Huang and N. Chen and P. Resta (Eds.), 2016 IEEE 16th International Conference on Advanced Learning Technologies (ICALT). 508-512.

[35] Hsiu-Ting Hung, Jie Chi Yang, Gwo-Jen Hwang, Hui-Chun Chu, and Chun-Chieh Wang. 2018. A scoping review of research on digital game-based language learning. Computers \& Education 126 (2018), 89-104.

[36] Gwo-Jen Hwang, Ting-Chia Hsu, Chiu-Lin Lai, and Ching-Jung Hsueh. 2017. Interaction of problem-based gaming and learning anxiety in language students' English listening performance and progressive behavioral patterns. Computers \& Education 106 (2017), 26-42.

[37] Gwo-Jen Hwang and Siang-Yi Wang. 2016. Single loop or double loop learning: English vocabulary learning performance and behavior of students in situated computer games with different guiding strategies. Computers \& Education 102 (2016), 188-201.

[38] Dell Hymes. 1972. On Communicative Competence. Penguin, Harmondsworth.

[39] Nikolai Ilinykh, Sina Zarrieß, and David Schlangen. 2019. Meetup! a corpus of joint activity dialogues in a visual environment. In In Proceedings of the 23rd Workshop on the Semantics and Pragmatics of Dialogue (SemDial 2019). London, UK.

[40] W. Michael Reed Jonathan deHaan and Katsuko Kuwada. 2010. The Effect of Interactivity with a Music Video Game on Second Language Vocabulary Recall. Language Learning \& Technology 14, 2 (2010), 74-94.

[41] Alan G. Kamhi and Hugh W. Catts. 2012. Language and reading disabilities (3rd Edition). Pearson/Allyn \& Bacon.

[42] M.J. Kieffer and N.K. Lesaux. 2008. The Role of Derivational Morphology in the Reading Comprehension of Spanish Speaking English Language Learners. Reading and Writing 21 (2008), 783-804. https://doi.org/10.1007/ s11145-007-9092-8

[43] Michael J. Kieffer and Nonie K. Lesaux. 2012. Direct and Indirect Roles of Morphological Awareness in the English Reading Comprehension of Native English, Spanish, Filipino, and Vietnamese Speakers. Language Learning 62, 4 (2012), 11701204. https://doi.org/10.1111/j.1467-9922.2012.00722.x arXiv:https://onlinelibrary.wiley.com/doi/pdf/10.1111/j.14679922.2012.00722.x

[44] John R. Kirby and Peter N. Bowers. 2017. Morphological instruction and literacy: Binding phonological, orthographic, and semantic features of words. Theories of reading development 15 (2017), 437.

[45] John R. Kirby and Peter N. Bowers. 2018. The effects of morphological instruction on vocabulary learning, reading, and spelling. In R. Berthiaume and D. Daigle and A. Desrochers (Eds.), Morphological processing and literacy development: Current issues and research. , 217-243 pages.

[46] John R. Kirby, S. Helene Deacon, Peter N. Bowers, Leah Izenberg, Lesly Wade-Woolley, and Rauno Parrila. 2012. Children's morphological awareness and reading ability. Reading and Writing: An Interdisciplinary fournal 25 (2012), 389-410. https://doi.org/doi:10.1007/s11145-010-9276-5

[47] John R. Kirby, Alain Desrochers, Leah Roth, and Sandy S. V. Lai. 2008. Longitudinal predictors of word reading development. Canadian Psychology/Psychologie canadienne 49, 2 (2008), 103-110. https://doi.org/10.1037/0708-5591.49. 2.103

[48] Panagiotis Kosmas, Andri Ioannou, and Panayiotis Zaphiris. 2019. Implementing embodied learning in the classroom: effects on children's memory and language skills. Educational Media International 56, 1 (2019), 59-74. 10.1080/ 09523987.2018.1547948

[49] Panagiotis Kosmas and Panayiotis Zaphiris. 2019. Embodied Interaction in Language Learning: Enhancing Students' Collaboration and Emotional Engagement. In In IFIP Conference on Human-Computer Interaction. Springer, 179-196.

[50] Stephen Krashen. 1987. Principles and Practice in Second Language Acquisition. Prentice International.

[51] Nonie K. Lesaux, Michael J. Kieffer, S. Elizabeth Faller, and Joan G. Kelley. 2010. The effectiveness and ease of implementation of an academic vocabulary intervention for linguistically diverse students in urban middle schools. Reading Research Quarterly 45, 2 (2010), 196-228. https://doi.org/10.1598/RRQ.45.2.3

[52] Kyle C. Levesque, Michael J. Kieffer, and S. Hélène Deacon. 2017. Morphological awareness and reading comprehension: Examining mediating factors. Fournal of Experimental Child Psychology 160 (2017), 1-20. https://doi.org/10.1016/j jecp.2017.02.015 
[53] Jiping Li and Xiaohui Yang. 2020. Game-Based 3D Virtual Environment for Learning Japanese Language and Culture. In Proceedings of the 2020 4th International Conference on Electronic Information Technology and Computer Engineering (EITCE 2020). Association for Computing Machinery, New York, NY, USA, 1147-1152. https://doi.org/10.1145/3443467. 3443920

[54] Miao Li and John R. Kirby. 2012. Breadth and depth of vocabulary knowledge in second language reading.

[55] Chi-Jen Lin, Gwo-Jen Hwang, Qing-Ke Fu, and Jing-Fang Chen. 2018. A flipped contextual game-based learning approach to enhancing EFL students' English business writing performance and reflective behaviors. Fournal of Educational Technology \& Society 21, 3 (2018), 117-131.

[56] Wei-Chen Lin, Hung-Tzu Huang, and Hsien-Chin Liou. 2013. The effects of text-based SCMC on SLA: A meta analysis. Language Learning \& Technology 17, 2 (2013), 123-142.

[57] Peter D. MacIntyre. 2007. Willingness to communicate in the second language: Understanding the decision to speak as a volitional process. Modern Language fournal 91 (2007), 564-576.

[58] Jonathan Marquez. 2018. Designing Card Games for Learning the Pragmatics of a Second Language. In Proceedings of the 2018 Annual Symposium on Computer-Human Interaction in Play Companion Extended Abstracts (CHI PLAY '18 Extended Abstracts). Association for Computing Machinery, New York, NY, USA, 45-49. https://doi.org/10.1145/3270316.3270610

[59] Jon F. Miller, Karen Andriacchi, and Ann Nockerts. 2011. Assessing language production using SALT software: A clinician's guide to language sample analysis (2nd Edition). Salt Software, LLC, Middleton, WI.

[60] Jon F. Miller and Aquiles Iglesias. 2015. Systematic Analysis of Language Transcripts (SALT), Version 16 [Computer software].

[61] Mohammed Ali Mohsen. 2016. The use of computer-based simulation to aid comprehension and incidental vocabulary learning. Journal of Educational Computing Research 54, 6 (2016), 863-884.

[62] William E. Nagy, Joanne F. Carlisle, and Amanda P. Goodwin. 2014. Morphological Knowledge and Literacy Acquisition. fournal of Learning Disabilities 47, 1 (2014), 3-12. https://doi.org/10.1177/0022219413509967

[63] National Institute of Child Health and Human Development. 2000. Teaching children to read: An evidence based assessment of the scientific literature on reading and its implications for reading instruction.

[64] Wen Fu Pan. 2017. The effects of using the Kinect motion-sensing interactive system to enhance English learning for elementary students. Educational Technology \& Society 20, 2 (2017), 188-200.

[65] Jian-E Peng. 2014. Willingness to Communicate in the Chinese EFL University Classroom: An Ecological Perspective. Multilingual Matters.

[66] Charles A. Perfetti and Joseph Stafura. 2014. Word knowledge in a theory of reading comprehension. Scientific Studies of Reading 18, 1 (2014), 22-37. https://doi.org/10.1080/10888438.2013

[67] Mark Peterson. 2010. Massively Multiplayer Online Role-Playing Games as Arenas for Second Language Learning Computer Assisted Language Learning 25, 3 (2010), 429-439.

[68] Mark Peterson. 2013. Computer Games and Language Learning. Palgrave Macmillan, New York.

[69] Mark Peterson. 2016. The use of massively multiplayer online role-playing games in CALL: An analysis of research. Computer Assisted Language Learning 29, 7 (2016), 1181-1194.

[70] Paul S. Rama, Rebecca W. Black, Elizabeth van Es, and Mark Warschauer. 2012. Affordances for second language learning. ReCALL (2012), 322-338.

[71] Jim Ranalli. 2008. Learning English with The Sims: Exploiting authentic computer simulation games for L2 learning. Computer Assisted Language Learning 21, 5 (2008), 441-455.

[72] Yolanda A Rankin, McKenzie McNeal, Marcus W Shute, and Bruce Gooch. 2008. User-centered game design: evaluating massive multiplayer online role playing games for second language acquisition. In ACM Sandbox.

[73] Yolanda A Rankin, Deidre Morrison, McKenzie McNeal, Bruce Gooch, and Marcus W Shute. 2009. Time will tell: in-game social interactions that facilitate second language acquisition. In In R. Young (Ed.), 4th International Conference on Foundations of Digital Games. 161-168.

[74] Hayo Reinders. 2012. Digital Games in Language Learning and Teaching. Palgrave Macmillan.

[75] Hayo Reinders and Sorada Wattana. 2012. Talk to me! Games and students' willlingness to communicate. Palgrave Macmillan. 156-187 pages.

[76] Jonathon Reindhardt and Jullie M. Sykes. 2012. Conceptualizing Digital Game-mediated L2 Learning and Pedagogy: game-enhanced and game-based research and practice. Palgrave Macmillan, 32-49.

[77] Jonathon Reindhardt and Julie M. Sykes. 2014. Digital Game and Play Activity in L2 Teaching and Learning. Language Learning \& Technology 18, 2 (2014), 2-8.

[78] Mercedes Rico, J. Enrique Agudo, and Hector Sánchez. 2015. Language learning through handheld gaming: A case study of an English course with engineering students. Journal of University Computer 21, 10 (2015), 1362-1378.

[79] Johnny Saldana. 2009. The Coding Manual for Qualitative Researchers. Sage, Thousand Oaks, CA.

[80] Jacobijn Sandberg, Marinus Maris, and Pepijn Hoogendoorn. 2014. The added value of a gaming context and intelligent adaptation for a mobile learning application for vocabulary learning. Computers \& Education 76 (2014), 119-130. 
doi:10.1016/j.compedu.2014.03.006

[81] David Schlangen. 2019. Natural language semantics with pictures: Some language \& vision datasets and potential uses for computational semantics. In Proceedings of the International Conference on Computational Semantics (IWCS).

[82] Norbett Schmitt and Diane Rae Schmitt. 1993. Identifying and Assessing Vocabulary Learning Strategies. Thai TESOL Bulletin 5, 4 (1993), 27-33.

[83] Pia Sundqvist and Liss Kerstin Sylven. 2012. World of VocCraft: computer games and Swedish learners' L2 vocabulary. Palgrave Macmillan. 237-267 pages.

[84] Julie M. Sykes. 2005. Synchronous CMC and pragmatic development: Effects of oral and written chat. CALICO 22 (2005), 399-431.

[85] Julie M. Sykes. 2013. Multiuser Virtual Environments: learner apologies in Spanish. In N. Taguchi, \& f. Sykes, Technology in Interlanguage Pragmatics Research and Teaching. John Benjamins' Language Learning and Teaching Series (2013).

[86] Sana Tibi and John R. Kirby. 2019. Reading in Arabic: How Well Does the Standard Model Apply? Journal of Speech, Language, and Hearing Research 62, 4 (2019), 993-1014.

[87] Laura Verga and Sonja A. Kotz. 2017. Help me if I can't: Social interaction effects in adult contextual word learning. Cognition 168 (2017), 76-90. https://doi.org/10.1016/j.cognition.2017.06.018

[88] Ludo Verhoeven, Marinus Voeten, and Anne Vermeer. 2019. Beyond the simple view of early first and second language reading: The impact of lexical quality. fournal of Neurolinguistics 50 (2019), 28-36. https://doi.org/10.1016/j.jneuroling 2018.03.002

[89] Richard K. Wagner, Joseph K. Torgesen, and Carol A. Rashotte. 1999. Comprehensive Test of Phonological Processes. PRO-ED Publishing, Inc., Austin, TX.

[90] Chun-Wang Wei, Hao-Yun Kao, Hsin-Hsien Lu, and Yi Chun Liu. 2018. The effects of competitive gaming scenarios and personalized assistance strategies on English vocabulary learning. Fournal of Educational Technology \& Society 21 , 3 (2018), 146-158.

[91] Ting-Ting Wu and Yueh-Min Huang. 2017. A mobile game-based English vocabulary practice system based on portfolio analysis. Educational Technology \& Society 20, 2 (2017), 265-277.

[92] Shelly Shwu-Ching Young and Yi-Hsuan Wang. 2014. The game embedded CALL system to facilitate English vocabulary acquisition and pronunciation. Educational Technology \& Society 17, 3 (2014), 239-251.

[93] Dongbo Zhang and Keiko Koda. 2012. Contribution of morphological awareness and lexical inferencing ability to L2 vocabulary knowledge and reading comprehension among advanced EFL learners: testing direct and indirect effects. Reading and Writing 25, 5 (2012), 1195-1216. https://doi.org/10.1007/s11145-011-9313-z

[94] Jie Zhang, Tzu-Jung Lin, Yu Liu, and William E. Nagy. 2020. Morphological Awareness and Reading Comprehension: Differential mediation mechanisms in native English speakers, fluent English learners and limited English learners. fournal of Experimental Child Psychology 199 (2020), 1-20.

[95] Dongping Zheng, Michael Bischoff, and Betsy Gilliland. 2015. Vocabulary learning in massively multiplayer online games: Context and action before words. Educational Technology Research and Development 63, 5 (2015), 771-790. 10.1007/s11423-015-9387-4

[96] Dongping Zheng, Manuela Maria Wagner, Michael F. Young, and Robert A. Brewer. 2009. Negotiation for Action: English Language Learning in Game-Based Virtual Worlds. The Modern Language fournal 93, 4 (2009), 489-511. http://www.jstor.org/stable/25612228

[97] Ying Zheng. 2008. Anxiety and Second/Foreign Language Learning Revisited. Canadian fournal for New Scholars in Education 1, 1 (2008), 1-12.

[98] Yu Zhongghen. 2018. Differences in serious game-aided and traditional English vocabulary acquisition. Computers \& Education 127 (2018), 214-232.

[99] Di Zou, Yan Huang, and Haoran Xie. 2019. Digital game-based vocabulary learning: where are we and where are we going? Computer Assisted Language Learning 0, 0 (2019), 1-27. https://doi.org/10.1080/09588221.2019.1640745 arXiv:https://doi.org/10.1080/09588221.2019.1640745

Received February 2021; revised June 2021; accepted July 2021 